\title{
Studi Tentang Faktor Penyebab Anak Putus Sekolah di Kenagarian Air Manggis Kecamatan Lubuk Sikaping
}

\author{
Nurul Fauzi, ${ }^{1}$ Yurni Suasti ${ }^{2}$ \\ Pendidkan Geografi \\ Fakultas Ilmu Sosial Universitas Negeri Padang \\ Email : nurulfauzi130@gmail.com
}

\begin{abstract}
ABSTRAK
Penelitian ini bertujuan untuk memperoleh informasi, membahas dan memberi gambaran tentang faktor penyebab anak putus sekolah di Kenagarian Air Manggis Kecamatan Lubuk Sikaping dilihat dari, pertama : minat untuk bersekolah, kedua : kondisi ekonomi anak putus sekolah, dan ketiga : lingkungan tempat tinggal anak putus sekolah. Jenis penelitian ini adalah penelitian deskriptif kualitatif, dimana informan yang diambil sebagai sampling yaitu anak putus sekolah, dan pemilihan informan menggunakan teknik purposive sampling. Teknik pengumpulan data yang digunakan adalah teknik observasi, wawancara, dan dokumentasi. Teknik analisis yang dilakukan dengan display data, reduksi data, penyajian data dan penarikan kesimpulan. Hasil penelitian menunjukkan faktor penyebab anak putus sekolah yaitu : (1) Minat belajar yang rendah, sementara disisi lain metode guru yang kurang bervariasi dalam mengajar, sehingga mereka tidak memahami. Disuatu sisi guru banyak memberikan tugas dan mereka tidak mengerjakannya lantaran tidak mengerti. (2) Pendapatan orang tua yang rendah berkisar antara Rp 500.000-Rp 1.500 .000 perbulan dengan pekerjaan pokok adalah bertani dan beban tanggungan antara 3-5 orang. (3) Pengaruh teman sebaya, ajakan dari teman sebaya untuk pergi bermain yang membuat mereka bolos sekolah hingga akhirnya mereka putus sekolah.
\end{abstract}

Kata kunci: pendidikan, anak putus sekolah

\begin{abstract}
This study aims to obtain information, discuss and provide an overview of the causes of drop outs in Kenagarian Air Manggis Kecamatan Lubuk Sikaping seen from, first: interest in school, secondly: the economic condition of drop out children, and third: . The type of this research is descriptive qualitative research, where the informant taken as sampling that is school dropout, and the selection of informant use purposive sampling technique. Data collection techniques used are observation techniques, interviews, and documentation. Analytical techniques performed with display data, data reduction, data presentation and conclusion. The result of the research shows that the causes of drop out are: (1) low learning interest, while on the other hand the teacher method is less varied in teaching, so they do not understand. On the one hand the teacher gives a lot of work and they do not do it because they do not understand. (2) Low parent income ranges from $R p$ 500,000 to Rp 1,500,000 per month with basic work being farming and dependent burden of 3-5 people. (3) Peer influence, invitation from peers to go to play that makes them skip school until they drop out of school.
\end{abstract}

Keywords: education, drop outchildren

Artikel Ini Ditulis Dari Skripsi penulis dengan judul Faktor Penyebab Anak Putus Sekolah Dikenagarian Air manggis Kecamantan Lubuk Sikaping. Untuk Wisuda Periode Maret 2018 Dengan Pembimbing I Dra.Yurni Suasti, M.Si 


\section{PENDAHULUAN}

Pendidikan merupakan suatu kegiatan yang universal dalam kehidupan manusia, karena dimanapun dan kapanpun didunia terdapat pendidikan. Pendidikan pada hakikatnya merupakan usaha manusia untuk memuliakan manusia itu sendiri, yaitu untuk membudayakan manusia.

Tujuan pendidikan merupakan sesuatu yang penting, mengingat perjalanan setiap instusi memiliki visi yang jelas selalu di mulai dari tujuan. Demikian pula pendidikan yang kini menjadi harapan mengarahkan kehidupan yang lebih baik hendaknya selalu berangkat dari tujuan yang akan dicapai. Dalam UU Sistem Pendidikan Nasional No. 20 Tahun 2003 "Tujuan pendidikan adalah untuk berkembangnya potensi peserta didik agar menjadi manusia yang beriman dan bertakwa kepada Tuhan Yang Maha Esa, berakhlak mulia, sehat, berilmu cakap, kreatif, mandiri, dan menjadi warga Negara yang demokratis, serta bertanggung jawab".

Pembangunan aspek di bidang pendidikan juga telah diatur sesuai dengan arah dan tujuanya yang tercantum dalam Undang-Undang Dasar 1945 pada alinea ke empat dalam kalimat mencerdaskan kehidupan bangsa, dan selanjutnya dijabarkan dalam batang tubuh undangundang dasar 1945 dalam pasal 31 ayat 1 dan 3 yaitu : Ayat 1 : tiap-tiap warga negara berhak mendapat pendidikan dan pengajaran. Ayat 3 : pemerintah mengesahkan dan menyelanggarakan suatu sistem pendididkan nasional yang menguatkan keimanan dan ketakwaan serta akhlak mulia dalam rangka mencerdaskan kehidupan bangsa yang diatur lebih lanjut dengan undang undang. Pernyataan tersebut mengandung arti penting bahwa negara dalam arti pemerintah yang ada di dalamnya melindungi dan bahkan memberi peluang yang seluas-luasnya dan sebesar-besarnya bagi setiap warga negara untuk mengenyam pendidikan formal seperti SD, SMP maupun SMA, atau melalui pendidikan informal. Hanya dengan melalui pendidikan formal maupun informal setiap individu mampu meningkatkan kualitas sumber daya yang dimilikinya baik secara teori maupun praktik.

Pendidikan dasar wajib yang dipilih Indonesia adalah 12 tahun yaitu pendidikan SD, SMP dan SMA apabila dilihat dari umur mereka yang waijb sekolah adalah 7-20 tahun. Pendidikan merupakan hak yang sangat fundamental bagi anak. Hak yang wajib dipenuhi dengan kerjasama dari orang tua masyarakat dan pemerintah Namun tidaklah mudah untuk merealisasikan pendidikan khususnya menuntaskan wajib belajar 12 tahun, karena pada kenyataannya masih banyak angka putus sekolah. Meskipun dasar hukum untuk peningkatan pendidikan sangat kuat, namun pendidikan masih merupakan persoalan yang dari tahun ke tahun terus meningkat. Dengan adanya permasalahan tersebut, maka dengan sendirinya banyak anak-anak yang tidak bependidikan daripada dibandingkan dengan anak yang berpendidikan.

Mengamati lebih jauh di Kenagarian Air Manggis Kecamatan Lubuk Sikaping masih banyak anak yang mengalami putus sekolah. Padahal sarana dan prasarana pendidikan di Kenagarian Air Manggis Kecamatan Lubuk Sikaping sudah terfasilitasi dengan baik. Sekolahsekolah mulai dari tingkat dasar sampai sekolah menengah atas ada di Kenagarian 
Air Manggis Kecamatan Lubuk Sikaping. Bahkan aksesbilitas untuk pergi ke sekolah-sekolah yang ada di Kenagarian Air Manggis Kecamatan Lubuk Sikaping bisa dapat dijangkau apabila sianak serius untuk mengecam pendidikan dengan baik. Adanya kondisi seperti itu seharusnya anak-anak di Kenagarian Air Manggis Kecamatan Lubuk Sikaping mendapatkan pendidikan dengan layak dan baik, karena sudah banyaknya tersedia sarana pendidikan untuk tempat mereka bersekolah.

Meskipun dari segi fisik daerah di Kenagarian Air Manggis Kecamatan Lubuk Sikaping sudah cukup baik untuk menjangkau dan mendapatkan pendidikan, tapi masih banyak anak-anak di Kenagarian Air Manggis Kecamatan Lubuk Sikaping yang putus sekolah di usia yang seharusnya wajib untuk mendapatkan pendidikan di sekolah. Berdasarkan data yang diperoleh dari penuturan aparat Kenagarian Air Manggis pada 15 Oktober 2015 waktu dilakukan pengambilan data sementara jumlah anak yang putus sekolah mulai dari tingkat Sekolah Dasar sampai Sekolah Menengah Atas atau Madrasah Aliah sederajat untuk wilayah Kenagarian Air Manggis.

Tabel 1.Anak Putus Sekolah di

Nagari Air Manggis, Kecamatan
LubukSikaping

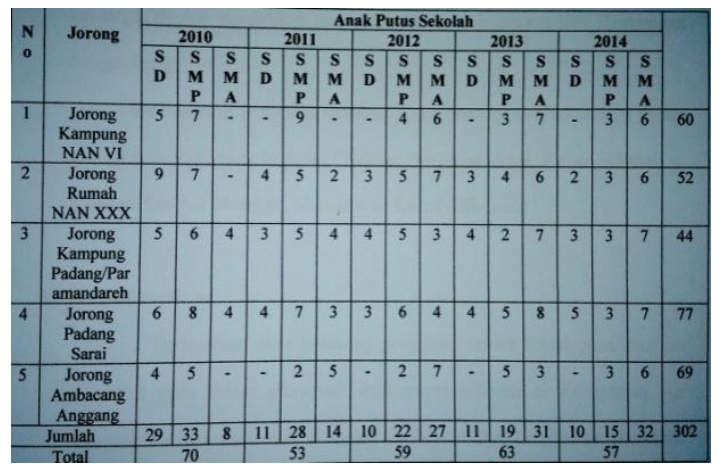

Sumber : Kantor Wali Nagari Air Manggis tahun 2015
Ditemukan bahwa anak yang putus sekolah tersebut terjadi dikarenakan berbagai macam alasan, diantaranya adalah faktor anak, faktor ekonomi dan lingkungan tempat tinggal.

Berdasarkan keterangan aparat kenagarian air manggis, jumlah anak putus sekolah sangat banyak sekali, untuk mengetahui faktor yang menyebabkan anak putus sekolah, maka diperlukan suatu penelitian. Peneliti mencoba mencari tahu penyebab anak putus sekolah yang ada di Kenagarian Air Manggis Kecamatan Lubuk Sikaping. Peneliti mencoba menguraikan faktor penyebab anak putus sekolah yang akan dilihat dari beberapa faktor dimana menurut Baharuddin (2012:29) faktor penyebab anak putus sekolah dapat dilihat dari faktor (1) intern yaitu dilihat dari faktor minat anak yang putus sekolah (2) ekstern dimana dlihat dari biaya atau kondisi ekonomi keluarga, juga pengaruh dari lingkungan tempat tinggal. Berdasarkan fenomena tersebut, maka peneliti menjadikannya dalam sebuah penelitian yang berjudul "Faktor Penyebab Anak Putus Sekolah di Kenagarian Air Manggis, Kecamatan Lubuk Sikaping"

Tujuan penelitian berdasarkan pertanyaan penelitian di atas maka penelitian ini bertujuan untuk mengetahui dan mendeskripsikan tentang apa faktor penyebab anak putus sekolah di Kenagarian Air Manggis Kecamatan Lubuk Sikaping.

\section{METODOLOGI PENELITIAN}

Penelitian yang dilakukan termasuk penelitian kualitatif, dilaksanakan melalui proses induktif, yaitu berangkat dari konseptualisasi, kategorisasi, dan deskripsi dikembangkan atas dasar masalah yang terjadi dilapangan. Penelitian ini 
dilaksanakan di Nagari Air Manggis Kecamatan Lubuk Sikaping. Dalam pelaksanaannya penelitian ini akan dilakukan 3 bulan yaitu November 2016 Januari 2017. Subjek yang diwawancarai dalam penelitian ini adalah (1) anak putus sekolah berumur 7-20 tahun, (2) orang tua yang memiliki anak putus sekolah.

Dalam penelitian ini ada dua jenis data yang digunakan yaitu: data primer dan data sekunder. Sumber data dalam penelitian ini didapat melalui wawancara, sumber tertulis dan foto. Dengan alat pengumpulan data berupa buku catatan, tape recorder dan kamera. Dalam teknik pengumpulan datanya 1). Obserasi partisipatif dan 2). Wawancara. Agar penelitian ini valid, maka dalam penelitian ini digunakan teknik pemeriksaan keabsahan data, yaitu melalui triangulasi.

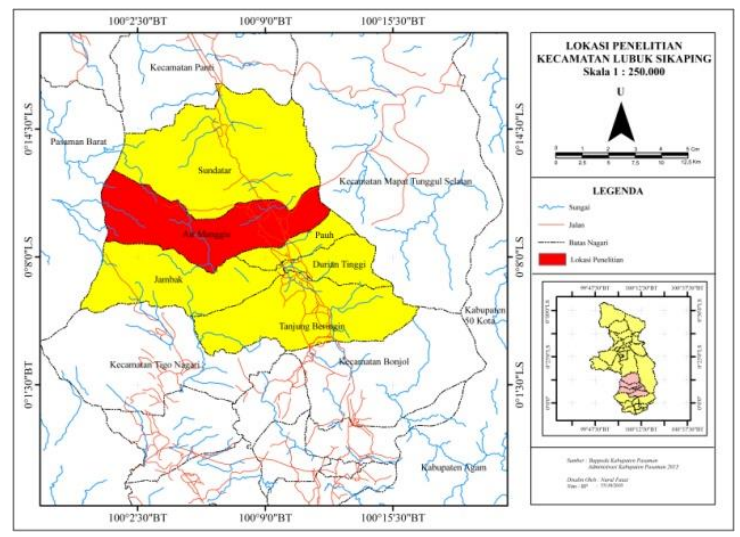

DESKRISI WILAYAH

Letak geografis Kenagarian Air Manggis secara astronomis terletak pada $100^{0} 2^{\prime} 30^{\prime \prime} \mathrm{BT}-100^{0} 15^{\prime} 30^{\prime \prime} \mathrm{BT}$ dan $0^{0} 1^{\prime} 30^{\prime \prime}$ LS - $0^{0} 14^{\prime} 30^{\prime \prime}$ LS dengan luas 81,6 Km, terdiri dari dataran lebih kurang $30 \mathrm{Km}$ dan perbukitan/pegunungan 51,6 Km.

Batas-batas wilayah Kenagarian Air Manggis adalah sebagai berikut:

a. Sebelah utara berbatas dengan Nagari Sundata.

b. Sebelah selatan berbatas dengan Nagari Pauh. c. Sebelah barat berbatas dengan Kecamatan Talamau (Pasaman Barat).

d. Sebelah timur berbatas dengan Nagari Muaro Sungai Lolo.

Kenagarian Air Manggis terdiri dari 5 Jorong yaitu ; Jorong Kampung NAN VI, Jorong Rumah NAN XXX, Jorong Kampung Padang/Paramandareh, Jorong Padang Sarai, Jorong Ambacang Anggang. Pusat Kenagaran terletak di Jorong Rumah NAN XXX. Sebagian besar daerah Kenagarian Air Manggis adalah pegunungan/perbukitan sekitar 51,6 Km disisi Timur dan Baratnya. Dataran sekitar $30 \mathrm{Km}$.

\section{PEMBAHASAN}

Pada pembahasan akan dibahas hasil penelitan tentang Faktor Penyebab Anak Putus Sekolah di Kenagarian Air Manggis Kecamatan Lubuk Sikaping. Analisis dari penelitian di atas dapat diuraikan beberapa faktor yang menyebabkan anak putus sekolah di Kenagarian Air Manggis Kecamatan Lubuk Sikaping adalah sebagai berikut :

Pertama: faktor minat bersekolah, berdasarkan minat dari anak putus sekolah di daerah penelitian ini, pada umumnya mereka kurang berminat untuk bersekolah lagi. Faktor mereka tidak beminat untuk sekolah lagi diantaranya adalah di pengaruhi oleh prestasi belajar anak itu sendiri. Dari beberapa anak putus sekolah tersebut mereka putus sekolah memang disebabkan kemampuan mereka terlalu lemah dalam mengelola pelajaran, semua pelajaran yang diberikan dari sekolah sulit untuk mereka pahami dan dimengerti sehingga ketika di sekolah mereka selalu mendapatkan nilai yang rendah, bahkan tidak naik kelas. Menurut Slameto yang dikutip oleh Djaali (2009:121), minat pada dasarnya adalah penerimaan akan suatu 
hubungan antara diri sendiri dengan sesuatu diluar diri.

Anak didik yang gagal dalam belajar dan tidak naik kelas ada dua kemungkinan yang terjadi pada dirinya. Pertama dia akan merasa malu terhadap teman-teman dan guru di sekolah karena ia tidak bisa seperti teman-temannya, maka ia malas untuk pergi ke sekolah. Kedua yaitu kegagalan dalam belajar akan menjadi cambuk baginya untuk belajar lebih giat dan rajin agar dapat menandingi temantemannya, dan kalau bisa lebih baik/tinggi dari teman-temannya semula. Tetapi sangat disayangkan, kemungkinan yang kedua ini jarang terjadi pada diri anak putus sekolah di Kenagarian Air Manggis, yang sering terjadi adalah kemungkinan pertama, bila gagal dalam belajar maka anak akan malas pergi ke sekolah dan meninggalkan sekolahnya yang belum selesai.

Disamping itu anak putus sekolah di daerah penelitian ini mereka mengeluhkan banyaknya tugas rumah yang diberikan guru di sekolahnya dan membuat mereka malas untuk mengerjakan tugas itu. Selain itu ada juga anak putus sekolah di daerah peneitian ini yang tidak mau sekolah karena dia bersekolah tidak disekolah yang ia inginkan.

Yang kedua: faktor kondisi ekonomi keluarga, faktor ekonomi yang dimaksudkan adalah ketidakmampuan keluarga si anak untuk membiayai segala proses yang dibutuhkan selama menempuh pendidikan atau sekolah dalam satu jenjang tertentu. Menurut Simbolon (2009:32) dalam kehidupan berkeluarga, peranan orang tua sangat menentukan dalam proses pemenuhan kebutuhan lahir dan batin, misalnya kebutuhan yang sangat komsumtif bagi anggota keluarganya.
Berdasarkan faktor kondisi ekonomi keluarga anak putus sekolah di daerah penelitian ini pada umumnya berasal dari keluarga yang kurang mampu. Pendapatan orang tua yang rendah berkisar antara Rp 500.000-Rp 1.500.000 perbulan dan jumlah tanggungan keluarga adalah antara 3-5 orang, dengan pekerjaan pokok adalah petani. Penghasilan dari orang tua mereka hanya mencukupi biaya kehidupan sehari-hari sehingga tidak mampu membiayai kebutuhan sekolah anakanaknya seperti uang masuk sekolah, uang pembangunan sekolah, uang seragam sekolah, buku tulis dan buku penunjang pelajaran serta biaya-biaya lainnya. Disuatu sisi anak yang putus sekolah ini tidak ada yang mendapatkan bea siswa. Dengan kondisi ekonomi keluarga yang tidak mampu membiayai kebutuhan sekolah anak-anaknya, para orang tua terpaksa mengorbankan pendidikan anak mereka dan bahkan anak membantu orang tua dalam mencukupi keperluan pokok untuk makan sehari-hari misalnya anak membantu orang tua ke sawah, karena dianggap meringankan beban orang tua dan meninggalkan sekolah dalam waktu yang cukup lama kemudian membuat mereka enggan untuk ke sekolah lagi, sehingga anak mereka putus sekolah di usia yang seharusnya wajib untuk mendapatkan pendidikan yang layak. Disamping itu sebagian dari orang tua anak putus sekolah di daerah penelitian ini ingin anaknya untuk sekolah lagi, tapi karena kondisi ekonomi mau tidak mau anaknya harus putus sekolah.

Dengan kondisi ekonomi keluarga yang tidak mampu, anak yang putus sekolah ada juga yang bekerja, mereka merasakan enaknya mencari uang sendiri dan enggan untuk bersekolah lagi sehingga akhirnya mereka putus sekolah. Dimana 
sebagian dari orang tua anak putus sekolah tidak mempedulikan hal tesebut.

Yang ketiga: faktor penyebab anak putus sekolah dari daerah penelitian ini adalah faktor lingkungan tempat tinggal. Lingkungan tempat tinggal yang dimaksud adalah pengaruh dari masyarakat sekitar, atau pengaruh dari pergaulan teman-teman sebaya. Teman bergaul yang baik akan berpengaruh baik pula terhadap diri siswa, begitu pula sebaliknya apabila siswa bergaul dengan teman yang tidak baik maka akan berpengaruh tidak baik pula terhadap diri siswa tersebut. Teman bergaul yang tidak baik misalnya yang suka bolos sekolah, aktif bermain ke warnet, begadang, keluyuran, pecandu rokok, dan lain-lain. Hal tersebut dapat menyebabkan siswa terseret ke ambang bahaya dan menyebabkan belajarnya jadi berantakan. Menurut Titaley (2012:41) anak yang tidak mampu membina pertemanan yang memuaskan juga akan merasa terpencil dan tidak bahagia. Bagi anak-anak ini, sekolah akan merupakan tempat yang tidak menyenangkan, dan akibatnya mereka dapat dan sering membolos atau putus sekolah sama sekali.

Berdasarkan lingkungan tempat tinggal penyebab anak putus sekolah adalah dipengaruhi oleh teman sebaya. Anak-anak putus sekolah tersebut sering bolos saat jam pelajaran/sekolah berlangsung dengan alasan lebih suka main-main dengan teman-teman di luar sekolah contohnya pergi main ke warnet dan bermain playtation yang membuat anak tidak ingat dengan waktu belajarnya. Selain itu, orang tua kurang mengontrol anaknya dalam menuntut ilmu untuk pergi ke sekolah dan mengontrol pergaulan anaknya. Sehingga anak-anaknya mudah terpengaruh oleh pergaulan teman-teman yang suka main-main di luar dibandingkan pergi ke sekolah dan akhirnya berhenti sekolah.

\section{DAFTAR PUSTAKA}

Baharuddin, 2012, teori belajar dan pembelajaran. Jogjakarta : Ar-Ruzz Media

Djaali. 2009. Psikologi Pendidikan. Jakarta : Bumi Aksara

Simbolon, Jolly.2009. Pengaruh Program Penguatan Keluarga Terhadap Sosial Ekonomi Warga Binaan Sos Desa Taruna Medan di Lingkungan II dan III Kelurahan Namo Gajah Kelurahan Medan Tuntungan (Skripsi). Medan : FIS. USU

Titaley, Merry.2012. Faktor-faktor Siswa Putus Sekolah pada Sekolah Menengah Pertama di SMPN 4 dan SMP Taman Siswa Jakarta Pusat (Tesis). Jakarta : Fakultas Ilmu Sosial dan Politik UI

UU No. 20 Tahun 2003, Tujuan

Pendidikan

UUD Tahun 1945 Pasal 31 ayat 1 dan ayat 3 